\title{
AVALIAÇÃO E REGULAÇÃO DA EDUCAÇÃO SUPERIOR: CONQUISTAS E IMPASSES
}

SiLKe Weber*

\begin{abstract}
RESUMO: O texto busca retraçar referências que foram se impondo no Brasil no debate e prática da avaliação do ensino superior e que têm informado um processo que, por necessariamente remeter à avaliação de mérito e de valor, está longe de conseguir adesão entusiasta de instituições e de seus principais agentes. Tais marcos orientadores, legislação e sua aplicação são concebidos como discurso, texto ou enunciado, cujo sentido se fixa no contexto de práticas articulatórias que envolvem agentes sociais em disputa por hegemonia de projetos de sociedade, em determinado espaço sócio-político. Indicam-se, à luz da tensão entre concepções de avaliação e de suporte à regulação, especialmente aquelas contidas na Lei do SINAES, algumas conquistas que teriam impacto positivo na elevação da qualidade da formação oferecida nesse nível de ensino e dos impasses que podem fazer prevalecer uma visão de avaliação que privilegie o desempenho individual de alunos, cursos e instituiçôes. Arrolam-se, ainda, aspectos que poderiam ter efeito positivo na redução de diferenças sociais que continuam a caracterizar o ensino superior brasileiro.
\end{abstract}

Palavras-chave: Crise da universidade. Avaliação da educação superior. Lei do SINAES.

\section{ASSESSMENT AND REGULATION OF HIGHER EDUCATION IN BRAZIL: CONQUESTS AND IMPASSES}

ABSTRACT: This text seeks to retrieve references that have imposed themselves in the Brazilian debate and practice of assessment of higher education and underpin a process that, since it

Doutora em Sociologia e professora do Programa de Pós-Graduação em Sociologia da Universidade Federal de Pernambuco (UfPE).E-mail: silke@elogica.com.br 
necessarily refers to the assessment of merit and value, is far from obtaining the enthusiastic adhesion of institutions and of their main agents. These orienting landmarks, the legislation and its application are conceived of as speeches, texts or utterances, whose meaning is fixed in the context of articulation practices that involve social agents contending for the hegemony of society projects, in given social-political spaces. To the light of the tension between conceptions of assessment and of support to regulation, especially those contained in the SINAES (Brazilian System to Assess Higher Education) law, we point out some conquests that have had a positive impact on the quality of the training offered at this level of teaching and the impasses that can lead to the prevalence of a vision of assessment privileging the individual performance of students, courses and institutions. We also list aspects that could help reduce the social differences that characterize Brazilian higher education.

Key words: University crisis. Assessment of higher education. SINAES law.

E

m 1988, Ernest House, que concebe a avaliação como determinação de valor de alguma coisa, julgada segundo critérios apropriados, explicitados e justificados (House, 1992), sugeriu a análise da inovação educacional sob três perspectivas: a tecnológica, a política e a cultural. A tecnológica, para o autor, se pauta pelo mundo da produção, tem interesse no produto ou na consecução de metas, focaliza a aprendizagem realizada, recorre a conceitos como entrada/saída, fluxos e tarefas, e valoriza a eficiência. A perspectiva política remete à imagem de negociação e volta-se para o contexto e os conflitos e compromissos entre grupos, emprega conceitos como poder, autoridade e interesses, e valoriza a legitimidade do sistema de autoridade. A perspectiva cultural, para ele, tem como imagem a comunidade, focaliza o conflito de valores, privilegia as relaçóes interpessoais e os significados, valorizando a conformidade e a tolerância.

Tais perspectivas podem ajudar a refletir sobre a questão da avaliação do ensino superior em curso no Brasil, tanto do ponto de vista educacional como institucional, porque permite superar a ótica dicotômica ou dualista que parece ter prevalecido no debate brasileiro, nas duas últimas décadas, conforme será tematizado mais adiante. 
Por outra parte, marcos orientadores de políticas educacionais relativas ao ensino superior podem ser concebidos como discurso, como texto ou enunciado dotado de forma própria, em função do tema e do interdiscurso trazidos por interlocutores em uma situação social presente que, todavia, se articula com o passado e o futuro desse nível de ensino e do país. O estabelecimento de sentido é realizado no próprio processo discursivo, envolvendo linguagem e práticas, no âmbito de disputas e negociações realizadas nas várias instâncias da vida social. Nessa ótica, o sentido se fixa no contexto de práticas articulatórias que envolvem agentes sociais em disputa por hegemonia em determinado espaço sócio-político. Dessa forma, alguns sentidos terminam por ser fixados em função de determinadas condições e passam a se constituir referências, que, entretanto, também podem ser rompidas como expressão do antagonismo social, cuja dinâmica costuma produzir identidades de objetos e de práticas e estabelecer fronteiras políticas, como anota Howarth (2000). Ambas as situações remetem a oscilações entre as possibilidades determinadas pela prática, no caso em estudo, debates e experiências sobre avaliação e regulação do ensino superior, aí incluídas as políticas educacionais e a legislação pertinente, construídas socialmente, no âmbito da disputa por projetos de sociedade.

É, pois, segundo tais perspectivas que se busca retraçar algumas referências que foram se impondo em relação à avaliação e à regulação do ensino superior brasileiro, cujo processo, por necessariamente remeter a julgamento de mérito e de valor da atividade educacional, está longe de conseguir a adesão de instituições e de seus principais agentes.

Em seguida, pretende-se, à luz da tensão entre concepções de avaliação educacional e institucional, e de seu papel na regulação da educação superior no Brasil e de alguns impasses, ressaltar conquistas que podem ensejar uma visão de avaliação que privilegie, simultaneamente, o desempenho individual de alunos, de cursos e de instituiçóes como indicadores de qualidade da formação promovida nesse nível.

Finalmente, busca-se indicar alguns elementos que mereceriam ser aprofundados, na medida em que poderiam ter efeito positivo para diminuir diferenças sociais que continuam a não ser enfrentadas no ensino superior brasileiro. 
Alguns aspectos do contexto do debate sobre avaliação do ensino superior

É quase unanimidade admitir-se que a discussão e a efetivação da avaliação da atividade educativa, como política pública, se inscrevem no contexto das reformas do Estado suscitadas pela crise do petróleo, quando ganhou destaque o aspecto gerencial para obtenção da eficiência e eficácia da ação pública nas várias dimensões. Nesse contexto, impôs-se a atividade avaliativa que, segundo House (2000), tem necessariamente marcas liberais, calcadas nas ideias de liberdade de escolha, individualismo e competição, conforme demandas da sociedade mercantil, competitiva e individualista, predominante no mundo ocidental. Haveria, no entanto, segundo o autor, possibilidade de explorar nas políticas sociais, caracterizadas como situação pública, a sua dimensão de decisão coletiva e democrática, enfoque que é aqui privilegiado.

Especialmente nos anos de 1970, acentuou-se a reflexão sobre a atuação e mudanças do ensino superior que, segundo Scott (1992; citado por Castro, 1995), "assumiu funções-chave, sociais e técnicas para a sociedade industrial e o Estado democrático", deixando a universidade "de ter qualquer projeto ideológico". As principais mudanças teriam ocorrido na expansão do acesso, caracterizada no Brasil pelo aumento da oferta de cursos de graduação por parte do setor privado (Martins, 2009), o que, segundo Sguissardi (2008), criou a possibilidade de subsumir expansão do ensino superior aos interesses privados/mercantis, transformando-o em mercado educacional.

Outra mudança importante foi a diferenciação das atividades do ensino superior, pela introdução da pós-graduação e da pesquisa acadêmica na universidade pública, principalmente. Até a década de 1990, continuava ínfima a abertura de cursos novos para novas carreiras, aspecto que pretendeu ser enfrentado pelo Decreto n. 6.096, de 27 de abril de 2007, que instituiu o Programa de Apoio ao Plano de Reestruturação e Expansão das Universidades Federais (REUNI). Entretanto, nenhuma política educacional foi desenvolvida para acompanhar a qualidade da formação oferecida nos cursos de graduação, que passaram a se multiplicar, credenciando automaticamente todos os seus concluintes. 
Tais problemas têm orientado a produção científica e técnica de diversos autores e de gestores de políticas públicas brasileiras, nas últimas décadas, que, no entanto, elegeram as questôes do financiamento e da autonomia das universidades públicas como principal foco de preocupação e de propostas de intervenção. Além disso, acerbas críticas têm sido feitas à formação em nível superior ser passível de ser negociada como mercadoria, de ser eficaz e pertinente na sua vinculação ao mundo do trabalho e o fato de serem estimuladas reformas deste nível de ensino.

A principal tônica do debate sobre reformas da educação superior, no Brasil, no contexto da globalização, é que ela induziria à perda de autonomia e de soberania nacional na definição de políticas educacionais. Tende a prevalecer a visão de que a discussão de tais temas remete a um processo mais amplo, de vinculação do país às diretrizes internacionais sobre educação em seus diferentes níveis, o que incluiria a Lei de Inovação Tecnológica e sua regulamentação (respectivamente, a Lei n. 10.973, de 2/12/2004, e o Decreto n. 5.562, de 11/10/2005), a Lei do SINAES (n. 10.861, de 14/4/2004), o PROUNI (Lei n. 11.096, de 13/01/2005) e, ainda, a Lei da Parceria Público/Privado (n. 11.079, de 30/12/2004), tal como demonstrado recentemente por Borges (2008). Não se considera, portanto, que reformas e processo avaliativo do ensino superior possam expressar tomada de consciência dos problemas reais desse nível de ensino e dos desafios comuns que se colocam à denominada sociedade do conhecimento, como a da gestão dos conhecimentos, por exemplo; consistindo as reformas, em certa medida, também, em uma resposta à globalização.

Esse debate vinha ganhando espaço no mundo ocidental, bastando lembrar as contribuições de Santos (1995), que localizou três crises da universidade - de hegemonia, de legitimidade e institucional -, postura que foi revista ou pelo menos redirecionada dez anos após, pelo mesmo autor, quando, no âmbito do que denomina luta por uma globalização alternativa, advoga a universidade como bem público (Santos, 2008). Nessa mesma linha, situam-se, entre outras, as contribuiçôes de Readings (1996), no livro Universidade em ruinas, e de Freitag (1995), no texto Naufrágio da universidade, cuja influência pode ser apreendida tanto no trabalho de Chauí (2001), que contrapõe a universidade como instituição social e como instituição operacional, assim 
como nos títulos de publicaçôes que aprofundaram tal debate, mediante a análise da relação entre produção de conhecimentos e sociedade, no início do ano 2000 - universidade em ruínas, escombros da universidade, naufrágio da universidade.

Além da comunidade científica, os reitores de universidades europeias tomaram parte desse debate e, em 1988, divulgaram o documento Magna Charta Universitatum, no qual discutem "o papel da universidade em uma sociedade em mudança e internacional", tema que será recorrente, conforme demonstra Borges (2007), e nos documentos elaborados no âmbito do Processo de Bolonha, iniciado em 1999. Esse debate atraíra, igualmente, a atenção dos organismos e entidades internacionais, a exemplo do Banco Interamericano para Reconstrução e Desenvolvimento (BIRD), que, em 1995, além de reformas no ensino superior de países em desenvolvimento, recomendava a "adoção de incentivos para a melhoria do seu desempenho". Recomendação de teor semelhante é feita no documento Declaração Mundial sobre Ensino Superior no Século XXI: visão e ação, aprovada na Conferência Mundial sobre o Ensino Superior de 1998, que destaca: "reforma dos sistemas e das instituições de ensino superior com vistas à melhoria de sua qualidade, pertinência e eficácia, reforçando relações com a sociedade, sobretudo com o mundo do trabalho", além "da ampliação do acesso e garantia de consideração do ensino superior como fator-chave do desenvolvimento, bem público e direito humano". Tais aspectos são reiterados nas Declarações de 2003, 2008 e de 2009, que reafirmam o papel essencial do ensino superior e da pesquisa para a resolução de problemas sociais de toda ordem, inclusive para a crescente necessidade de formação ao longo da vida.

No contexto desse debate, ganham destaque, evidentemente, a discussão e a prática da avaliação educacional e institucional do ensino superior que, no caso brasileiro, vale ressaltar, fora se delineando alguns anos antes dos diferentes documentos mencionados, conforme se observará a seguir.

\section{O debate sobre a avaliação do ensino superior no Brasil}

Uma primeira iniciativa para enfrentar o debate sobre a situação do ensino superior brasileiro, particularmente aquele capitaneado pelas 
universidades públicas, no âmbito da retomada do regime democrático, foi tomada pelo MEC, em 1983, quando instituiu o Programa de Avaliação da Reforma Universitária (PARU). Seu principal objetivo, entretanto, era apreender de que maneira a Reforma Universitária de 1968 fora implantada nas universidades públicas federais, ou seja, que tipo de modernização fora ali desencadeado pela Lei n. 5.540, de $28 / 11 / 1968$. Sua ênfase recaiu nos mecanismos de gestão e na produção e disseminação do conhecimento, na expectativa de que tal processo avaliativo pudesse subsidiar políticas específicas que propiciassem as mudanças percebidas como necessárias, iniciativa que, entretanto, findou por não produzir o efeito esperado.

A seguir, foram instituídas, também pelo mec, comissões especiais - Comissão Nacional de Reformulação do Ensino Superior (1985), Grupo Executivo para a Reforma do Ensino Superior (GERES), em 1986 -, assim como foram realizados, igualmente, sob a égide do MEC, seminários voltados para o debate sobre a avaliação do ensino superior (1987/1988) como subsídio para a formulação de políticas governamentais pertinentes. Os documentos produzidos suscitaram fortes reaçôes, particularmente, por proporem, entre outros aspectos, a diversificação institucional - universidade de pesquisa e instituiçōes de ensino, sua hierarquização, flexibilidade curricular, visando ao mercado de trabalho, e o financiamento público mediante avaliação da execução de contratos de atividades e metas (contratos de gestão). Nesse mesmo período, entidades da sociedade civil, como o Conselho de Reitores das Universidades Brasileiras (CRUB) e o Sindicato Nacional de Docentes das Instituições de Ensino Superior (ANDES/SN), também produziram documentos (1988). Este último, por exemplo, em clara resposta aos documentos oficiais, passou a defender a adoção de um "padrão único de qualidade para as universidades", formato institucional eleito como modelo de formação de nível superior, uma vez que associa, necessariamente, o ensino, a pesquisa e a extensão.

Comissões de especialistas de ensino foram instituídas, no final do Governo Collor (1992), com "a incumbência de prestar assessoria à Secretaria de Ensino Superior (SESU/MEC), para instalar um processo permanente de avaliação, acompanhamento e melhoria dos padrões de qualidade do ensino superior, nas diversas áreas de formação científica e profissional" (art. $1^{\circ}$ da Portaria n. 287, de 10 de dezembro de 
Avaliação e regulação da educação superior: conquistas e impasses

1992). Tais Comissões tiveram, em 1996, papel importante na elaboração das Diretrizes Curriculares dos Cursos de Graduação (1997) e forneceram avaliadores para a verificação das condiçôes institucionais e de autorização e reconhecimento de cursos.

É, pois, em um cenário perpassado pelo debate sobre a crise da universidade brasileira e a necessidade de rever seus rumos que é formulada uma proposta de enfrentamento de muitos dos seus problemas, mediante a criação da Comissão Nacional de Avaliação (Portaria n. 130, de 14 de julho de 1993), com "o objetivo de estabelecer diretrizes e viabilizar a implementação do processo de avaliação institucional nas universidades brasileiras" (art. $1^{\circ}$ ). Tal decisão, inspirada no processo pioneiro de avaliação institucional da UNICAMP, protagonizado pelo então pró-reitor, prof. José Dias Sobrinho, deu origem ao Programa de Avaliação Institucional das Universidades Brasileiras (PAIUB) (Decretos n. 2.026, de 10/10/1996, e n. 2.306, de 19/08/1997, e Portaria MEC n. 302, de 07/04/1998). Este Programa focalizava a avaliação institucional na perspectiva de melhoria da qualidade da formação oferecida, sobretudo aquela ministrada na graduação, iniciativa que suscitou, de imediato, o interesse de 43 reitores e pró-reitores de diversas universidades federais, 30 das quais deram início ao processo de avaliação institucional. Vale destacar que, também, algumas universidades comunitárias se associaram a esse esforço de conhecer a dinâmica institucional e saber se eram cumpridas as finalidades e prioridades por elas definidas. Limites e possibilidades desse Programa foram destacados por Gomes (2003).

Vale lembrar que, nessa ocasião, a avaliação da formação promovida no nível de pós-graduação stricto sensu, delineada a partir do estabelecido pelo Parecer n. 977, do então Conselho Federal de Educação, estava praticamente consolidada pela CAPES e já materializada em processo contínuo de acompanhamento da implementação de cursos de mestrado e de doutorado. Tal processo, oriundo do corpo diretor da CAPES, na segunda metade da década de 1970, procurava definir parâmetros e critérios para o estabelecimento de patamares nacionais de qualidade acadêmica, referências que, desde então, vêm sendo continuamente aperfeiçoadas ou seguidamente alteradas, com a ativa participação da comunidade científica das diversas áreas, bem como das próprias instituições submetidas à avaliação periodicamente. 
Ressalte-se, por outra parte, que nesse período - meados dos anos de 1980 e anos de 1990 -, ganhavam igualmente visibilidade iniciativas locais de avaliação educacional realizada por meio do uso de provas ou testes, elaborados com a colaboração de universidades públicas, em especial. No âmbito de estados e de municípios, focalizava-se, então, a análise do desempenho escolar do aluno do ensino fundamental. Tal experiência certamente serviu de base para a generalização da avaliação educacional, ou do desempenho escolar do aluno, em nível nacional, incluindo o ensino médio, com a criação do Sistema de Avaliação da Educação Básica (SAEB), em meados dos anos de 1990, e do Exame Nacional de Ensino Médio (ENEM), em 1999. Ainda, na perspectiva da avaliação educacional então prevalecente, foi instituído, em meados da década de 1990, em relação ao ensino superior, o Exame Nacional de Cursos (ENC), transformado, mais adiante e com a sanção da Lei n. 10.861/2004, que institui o Sistema Nacional de Avaliação da Educação Superior (Lei do SINAES), em Exame Nacional de Avaliação do Desempenho do Estudante (ENADE).

Pode-se afirmar, portanto, que, entre meados da década de 1980 e da década de 1990, houve paulatina institucionalização da avaliação educacional periódica, entendida como aferição de índices de aprendizagem obtidos nos diferentes níveis de ensino, inclusive do ensino superior. A avaliação do ensino superior foi promovida pela Lei n. 9.131/ 1995, que criou o Conselho Nacional de Educação. Essa Lei, de certo modo, legitimava e dava materialidade a preocupações que perpassavam a definição de políticas públicas relativas à educação superior, desde 1986, quando o ensino superior tornou-se objeto de recomendações por parte de diferentes Comissões instituídas pelo governo federal, conforme mencionado. Essa Lei respaldou a generalização, no país, de outra forma de avaliação, voltada para as instituições, mas o fez desconsiderando o processo de construção e execução do PAUIB, que fora calcado na indução à busca de melhoria da qualidade da atuação institucional no ensino superior, mediante a adesão de universidades e de instituições de ensino superior (IES). Com efeito, o formato que se institucionalizou obedece a determinados critérios e atinge a todas as IES, se avocando o MEC a ação de coordenador da política educacional.

Em ambos os casos, o da avaliação educacional e da avaliação institucional, o processo avaliativo deveria desencadear processos de 
mudança no interior das próprias IEs, bem como subsidiar o estabelecimento de padróes de qualidade a serem por elas atingidos, principal foco dos processos de regulação do ensino superior desenvolvido pelo poder público. Institui-se, assim, a tensão entre avaliação e regulação, no debate sobre a qualidade da formação em nível superior e acerca das políticas educacionais formuladas pelo Ministério da Educação.

Com efeito, a avaliação do ensino superior, procedida entre 1995 e 2004, mediante o ENC, centrava-se nos resultados da formação pela averiguação dos conhecimentos adquiridos pelo aluno ao longo do curso. O conceito do curso, juntamente com o conceito obtido na Avaliação das Condições de Ensino (ACE), indicava o lugar que a IES ocupava entre as suas congêneres, forma claramente indutora de competição. Tal prática foi objeto de críticas diversas, que findaram por contrapor tônicas que, no debate sobre avaliação no Brasil, foram prevalecendo, como se verá a seguir.

Algumas tônicas do processo de avaliação na primeira década do século XXI

Embora seja corrente a crítica a visões dicotômicas ou dualistas, é frequente admitir-se a confrontação de pelo menos duas concepções de avaliação do ensino superior brasileiro que, por sua vez, remetem a concepções congruentes de universidade e de formação em nível superior: Silva Junior, Catani e Gilioli (2003, p. 11), por exemplo, contrapõem a avaliação imposta do exterior e a visão de "universidade privatista, produtivista e utilitarista" à "avaliação global, voluntária e de forma participativa" e a visão de "universidade pública, com realce para sua função social”. No primeiro caso, haveria "um sistema de avaliação centralizadora, pautado pela regulação, padronização e controle contabilista dos 'produtos" que o ensino superior pode prover, sendo as IES vistas como "agências prestadoras de serviços, destinadas a obter 'resultados' que demonstrem a sua 'eficiência' na produção” (idem, p. 11) a ser mensurada quantitativamente, tendo o mercado como principal referência. Ou seja, recorrendo a House, anteriormente mencionado, ter-se-ia o predomínio do que esse autor denomina perspectiva tecnológica. As diferenças 
de desempenho, assim apreendidas, fundamentam o estabelecimento de rankings e o incentivo à concorrência entre IES, e contribuem para a concomitante transformação da formação em nível superior em mercadoria. Este formato teria sido o que caracterizaria as políticas de ensino superior do Governo Fernando Henrique Cardoso (1995-2002).

No segundo caso, "a avaliação não seria apenas um meio de controle e medição da eficiência acadêmico-administrativa, mas principalmente lógica indutora de desenvolvimento institucional" (idem, p. 12), proporcionando "aperfeiçoamento da dinâmica e dos processos internos das IES, bem como mudanças qualitativas nos processos de gestão" com vistas ao cumprimento "da efetividade social e científica das IES" (p. 13). Ou seja, ainda recorrendo a House, uma combinação entre a perspectiva política, em que predomina a negociação, e a perspectiva cultural de respeito aos sentidos construídos na prática institucional, sem descurar, evidentemente, da aferição de resultados.

De um modo geral, este último formato caracterizaria, respectivamente, as políticas públicas corporificadas no PAIUB e, mais adiante, aquelas formuladas a partir do início do Governo Lula, quando, por decisão ministerial, foi constituída, em abril de 2003, a Comissão Especial de Avaliação da Educação Superior, no contexto do debate sobre universidade, realizado em Brasília, no âmbito do Seminário Universidade: porque e como reformar? (agosto de 2003) e do Seminário Internacional Universidade XXI - novos caminhos para a educação superior: o futuro em debate (novembro de 2003). Aquela Comissão, presidida pelo prof. José Dias Sobrinho, teve a "finalidade de analisar, oferecer subsídios, fazer recomendaçōes, propor critérios e estratégias para a reformulação dos processos e políticas de avaliação da educação superior e elaborar a revisão crítica dos seus instrumentos, metodologias e critérios utilizados". Em resumo, partir da prática de avaliação institucionalizada, examiná-la criticamente e indicar caminhos para que as IES pudessem cumprir a efetividade científica e social que lhes é inerente.

Cabe chamar a atenção, desde já, para a redenominação operada de ensino superior para educação superior, com interesse claro de enfatizar a dimensão necessariamente formadora e crítica que tal nível de formação comporta e de relacionar o domínio do conhecimento, sua crítica e seu uso social. 


\section{A Comissão procurou:}

1) convergir em relação a uma concepção de avaliação como processo que vinculasse a dimensão formativa, realizada no âmbito de desenhos institucionais diferenciados, a um projeto de sociedade comprometido com a igualdade e a justiça social;

2) priorizar o estabelecimento de critérios e estratégias para a avaliação da formação graduada, considerando o elevado número de formandos por semestre letivo;

3) estabelecer critérios de avaliação de estudantes que incluíssem caminhos que sinalizassem uma perspectiva de auferir além do domínio do conhecimento, da cultura e da tecnologia característico de uma área específica, a visão crítica a respeito de sua contribuição para o enfrentamento de questóes centrais da atualidade nacional e internacional;

4) relacionar tais critérios à dinâmica institucional experimentada em desenhos institucionais diferenciados, ou seja, considerasse finalidade, tamanho e complexidade das IES.

A formulação da proposta foi acompanhada por debate social sistemático, mediante a realização de audiências públicas, debate que teve na defesa da forma de medir os resultados da aprendizagem dos alunos um de seus focos principais, culturalmente, ainda assimilada como principal indicador da qualidade da formação oferecida por uma IES, tanto no meio acadêmico, como na sociedade em geral.

A Comissão concebia a avaliação como necessariamente associada à regulação do Estado e admitia ter a sociedade o direito de conhecer como as IES estão realizando seus mandatos sociais relativos à disseminação e produção do conhecimento e à formação de cidadãos, que sejam também bons profissionais. Concebia a avaliação, portanto, como um processo estabelecido por um determinado agente, o Estado, com o propósito de acompanhar patamares de qualidade alcançados de modo a localizar potencialidades e possibilidades de avanço na consecução dos objetivos pretendidos ou necessidade de mudanças de rumo, constituindo a avaliação institucional parte das políticas públicas de educação superior. 
A Comissão adotava, portanto, a visão de avaliação como intervenção de natureza educativa, que tem como foco o processo formativo que as IES realizam. Procurava referir-se à própria especificidade da atuação institucional, entendendo que essa atuação produz efeitos imediatos na sociedade, entre outros motivos, pelo significativo contingente de graduados que semestralmente conclui estudos superiores. Além disso, considerava a necessária inserção de uma instituição formadora na experiência nacional e internacional de formação superior em uma área específica e os desafios impostos pela construção, na sociedade brasileira, de uma cultura democrática comprometida com a igualdade e a justiça social.

A Comissão tinha, assim, como diretriz, propor um sistema de avaliação que contribuísse para a transformação da educação superior, de modo a fazê-la corresponder aos anseios da sociedade por um país democrático. Tal sistema a ser construído pelo Estado deveria contribuir

(...) para preservar os valores acadêmicos fundamentais de liberdade e pluralidade de ideias, cultivar a reflexão filosófica, as letras e artes, o conhecimento científico e tecnológico, para valorizar as IES como estratégicas na implementação de políticas setoriais nas áreas científica, tecnológica e social, tendo as universidades públicas como referência. (p. 9)

O Sistema Nacional de Avaliação da Educação Superior (SINAES) é, pois, regido pelos princípios de que a educação superior constituiu direito social e dever do Estado, e a formação e a produção do conhecimento é relevante para o desenvolvimento conjunto da população e para o avanço da ciência. Os demais princípios dizem respeito ao fortalecimento dos valores éticos, visando melhorar compromissos institucionais, a dinâmica dos processos e das relaçôes, o respeito à identidade e à diversidade institucional, a globalidade expressa na integração dos instrumentos de regulação e de avaliação em uso pelo Estado e nas IES, a busca de legitimidade técnica e de legitimidade ética e política. Concebe, como principais atores do processo, os professores, os estudantes, os funcionários, dirigentes, ex-alunos, grupos sociais e, por conseguinte, utiliza vários instrumentos: a avaliação institucional, iniciada pela autoavaliação, seguida de avaliação externa, organizada pela Comissão Nacional de Avaliação da Educação Superior (CONAES), Censo do Ensino Superior, Cadastro de Perfil Institucional e Desempenho do Estudante (ENADE). 
A CONAES, vinculada ao Poder Executivo federal, de natureza colegiada, dotada de caráter deliberativo, constitui instância nacional autônoma e tem como tarefas estabelecer diretrizes para o processo de avaliação como um todo, articular avaliação à regulação, assegurar qualidade e coerência ao SINAES e promover o seu aperfeiçoamento.

Em relação ao processo instituído em decorrência da Lei n. 9.131/1995, que originou o Exame Nacional de Cursos (ENC) e estimulou a competição entre IES, a criação do SINAES representou uma conquista, na medida em que introduziu grande mudança no processo de avaliação da educação superior, que pode ser resumida nos seguintes pontos:

a) está focada na avaliação institucional;

b) combina autoavaliação com avaliação externa;

c) avaliação e regulação se alimentam mutuamente;

d) articula os diversos instrumentos mediante uma concepção global;

e) amplia a concepção de educação superior e de formação;

f) reorienta objeto da avaliação, sujeitos envolvidos e função dos avaliadores;

g) institui política de recrutamento e de capacitação de avaliadores;

h) substitui o ENC por processos globais;

i) valoriza processos formativos e abordagem qualitativa;

j) adapta instrumentos de avaliação vigentes à nova concepção;

1) introduz a meta-avaliação.

É evidente que tais mudanças suscitaram e continuam a suscitar reações não somente das IES que as deveriam vivenciar mediante adesão, mas também do órgão executor (INEP) dos novos processos a implantar. Vale lembrar que este organismo desenvolvera competência e adquirira conhecimento em relação aos instrumentos, de caráter eminentemente operacional que desenvolvera, da logística referente à sua implantação e também dos avaliadores. 


\section{Algumas tensões suscitadas pelo SINAES}

Uma das principais tensões dizia respeito, inicialmente, à resistência quanto à assunção pelo Estado do seu papel avaliador e, ao mesmo tempo, estimulador do caráter educativo e formativo de aprofundamento do compromisso e responsabilidade social das IES. Por outra parte, foi sendo explicitada a tensão entre um modelo de IES, a universidade pública e o respeito à identidade institucional, previsto pelo SINAES, tensão que persiste até o presente, como explicitação de uma disputa entre avaliadores e instituiçóes, sendo frequentemente fundamento para recursos impetrados pelas instituições e encaminhados à Comissão Técnica de Acompanhamento da Avaliação (CTAA). Cabe ainda mencionar a dificuldade dos avaliadores em trabalharem com indicadores de qualidade, em substituição à lista de requisitos, que caracterizava grande parte dos instrumentos de Avaliação das Condições de Ensino e de Avaliação de Cursos.

O estabelecimento inicial de diretrizes para a avaliação institucional, em lugar de resposta a tópicos ou itens que ressaltam resultados, foi considerado caminho adequado para as IES explorarem a dinâmica desencadeada pelo processo de autoavaliação e justificar decisóes por elas tomadas. Essa explicitação, de um lado, tinha a expectativa de produzir rico material, posto que confirmaria ou infirmaria junto aos avaliadores internos (comunidade acadêmica, coordenada pela Comissão Própria de Avaliação) a tônica de atuação da IES. Por outro lado, deveria fornecer aos avaliadores externos (comunidade circundante e instâncias de avaliação e de regulação) o referencial privilegiado pela IES, tornando plausível e credível a imagem pública que procura veicular. Esta imagem dá substrato à missão e desenvolvimento institucional, uma das dez dimensões consideradas, porque facilita a contraposição entre o almejado em determinado momento e conjuntura e o efetivado mais adiante.

Nessa perspectiva, cada IES realizaria a autoavaliação em função do desenho institucional que obteve no credenciamento ou que foi cristalizado no PDI que submeteu à apreciação dos órgãos estatais nos últimos anos. Para fazê-lo de forma convincente, a IES teria que contrapor o que realiza ao que é requerido nacional e internacionalmente da educação superior, referindo-se à história desse campo da educação no país e esclarecendo as bases da legitimação que foi obtendo ao longo de sua atuação institucional. 
O foco da avaliação, seja ela interna ou externa, seria, assim, a averiguação da consistência interna dos aspectos selecionados pela IES ao longo de seu processo avaliativo. Coube à CONAES estabelecer critérios qualitativos de avaliação que permitissem a comparação dos patamares de qualidade a que chegaram as diferentes IES, a partir dos quais seriam formulados indicadores de avanços ou retrocessos na qualidade da oferta de formação em nível superior no país.

Ora, a falta de clareza do que significa formar com qualidade quadros de nível superior, o que diferencia ensino superior, de formação universitária, formação profissional, de formação acadêmica, ensino superior, de educação superior, bem como que a tarefa formativa requer avaliação periódica do próprio formato institucional escolhido para realizá-la, torna ainda mais tensa e difícil a discussão acerca da efetivação de tal processo. O principal argumento utilizado pelas IES tem sido a excessiva subjetividade na qual se apoiaria tal formato, o que impediria comparaçóes e, portanto, classificações. O INEP, por sua vez, recorre ao argumento da complexidade decorrente do número de IES envolvidas. A resistência pouco a pouco se estendeu para além do formato a ser empregado para a autoavaliação institucional, atingindo, sobretudo, o formato de avaliação de cursos, que manteve o caráter operacional, até porque era exíguo o tempo disponível para evitar solução de continuidade no processo avaliativo.

Os instrumentos de avaliação de cursos, apesar de estarem em sua quarta versão, se não houver engano, têm sido objeto de contestação frequente, seja de parte da comunidade acadêmica e das instituições que os propõem ou os oferecem, seja dos próprios avaliadores.

Os avaliadores são selecionados, atualmente, a partir da inscrição por adesão, respeitados critérios públicos, e compõem o Banco de Avaliadores do Sistema Nacional de Avaliação da Educação Superior (BASis), formato que foi premiado pela UNESCO. Se bem que venham contribuindo para o processo de avaliação do ensino superior reputado como o maior do mundo, os avaliadores têm, também, frequentemente utilizado as suas instituições de origem como referência de avaliação, assim como declinado algumas vezes de exercer a sua capacidade de julgamento de valor e de mérito. Cabe ainda mencionar a dificuldade que têm tido os avaliadores de exercerem a sua capacidade de inferência, ao trabalharem com indicadores de qualidade da formação. 
Assim, lhes tem sido difícil, muitas vezes, decidir se o curso ou a instituição em avaliação atende ou não aos critérios inerentes a uma formação de qualidade na área, além de algumas vezes usarem o seu papel de avaliador para contestar o próprio processo ao qual aderiram, considerando qualquer iniciativa institucional como merecedora de destaque ou de crítica, introduzindo, portanto, um viés no processo avaliativo. Apresentam-se, dessa forma, frequentemente como porta-vozes da visão que privilegia o caráter diferenciador das IES, subsidiando a contestação do que foi definido como padrão mínimo de qualidade.

No que se refere ao ENADE, a pretensão de estender a avaliação do desempenho do aluno para todos os cursos oferecidos nas diversas áreas de conhecimento no Brasil, e de apreender o papel da IES na formação dos seus estudantes a cada ciclo de três anos, fez com que houvesse o recurso a amostras representativas de alunos ingressantes e concluintes dos cursos relacionados às áreas selecionadas para cada exame. Tal decisão encontra resistência na comunidade acadêmica, entre especialistas em avaliação e técnicos de organismos governamentais, que multiplicam argumentos contestadores dos critérios de definição das amostras, bem como a respeito da validade do conhecimento gerado da comparação do desempenho de ingressantes e concluintes sobre o efeito da IES na qualidade do desempenho estudantil, entre outros aspectos, por não abrangerem os mesmos estudantes. Por outra parte, é contestado, igualmente, o peso dado a fatores como titulação e regime de trabalho docente e às informaçôes de natureza socioeconômica e opiniōes sobre a instituição formadora, mencionadas pelos estudantes, aspectos que findaram incorporados no Conceito Preliminar de Cursos (СPC) e no Índice Geral de Cursos (IGC), indicadores recentemente criados como forma de dar visibilidade à avaliação e suporte para a regulação.

A pressão para concluir o primeiro ciclo do SINAES, estabelecido para 2009, fez com que o MEC tomasse algumas iniciativas para dar consequência à Avaliação de Curso e à Avaliação Institucional procedida, ou seja, dar concretude à regulação e à supervisão. Entre tais iniciativas situa-se a criação de índices que sintetizariam a situação de cursos e de IES, tais como o CPC e o IGC. Associado a tais índices, haveria mudanças nos procedimentos do processo avaliativo em curso, como visitas in loco das Comissões de Avaliação, ficando restrita 
às instituições que tinham obtido conceito inferior a 3, definido como padrão mínimo de qualidade. Ora, dessa forma, o ENADE termina sendo privilegiado, uma vez que ele é a principal fonte das variáveis consideradas na construção do CPC e também do IGC, havendo nítido esvaziamento da relevância dada à autoavaliação institucional.

De fato, o IGC pretende sintetizar para cada IES a qualidade de todos os seus cursos de graduação e de pós-graduação oferecidos em todos os seus campi. Este índice é composto pelo CPC e pelo conceito que a CAPES atribui aos seus cursos de pós-graduação, sendo a média ponderada pela distribuição dos alunos dos cursos de graduação e de pós-graduação.

O IGC 2008 calculado abrangeu 78\% das IEs cadastradas: 173 universidades, 131 centros universitários e 1.144 instituições de outra natureza. A maioria delas ficou com o IGC 3. Os IGC 4 e 5 foram obtidos, sobretudo, pelas universidades $(26,7 \%$ e $3,4 \%$, respectivamente) e pelas IES públicas $(30,2 \%$ e 5,3\%, respectivamente). Os IGC 1 e 2 foram obtidos pelas IES de outra natureza (cerca de $28 \%$ ), conforme dados divulgados pelo INEP à imprensa.

A ênfase dada à variável "desempenho do estudante", nos resultados obtidos pelas IES, finda por transformar a proposta do SINAES de avaliação como processo formativo em simples avaliação de resultados, com privilegiamento, portanto, da tônica tecnológica, segundo a concepção de House.

Do aqui exposto, em sucintas linhas, fica patente que a avaliação da educação superior continua na ordem do dia no Brasil, e que parece ter chegado o momento de proceder à meta-avaliação do modelo hoje vigente, para assegurar que o tamanho da oferta de ensino superior não constitua obstáculo ao seu aperfeiçoamento continuado. Esta parece uma condição para que a avaliação prevaleça sobre a regulação, consolidando a perspectiva de democratização do ensino superior com qualidade.

\section{Considerações finais}

A avaliação da educação superior, concebida como um sistema que integra normas legais, dinâmica institucional, e considera os diferentes desenhos existentes, informações e desempenho do aluno, 
pretendia deslocar o foco do estudante para enfatizar o processo global de formação. Visava estimular a melhoria da qualidade acadêmica e a gestão institucional das IES, ao articular a regulação, concebida como vigilância e ordenamento do Estado, e as condiçôes requeridas para realizar suas finalidades e objetivos, e entendia a avaliação como análise da concretização do compromisso social de formação por parte da instituição formadora.

Desse modo, a avaliação institucional deveria ser entendida como parte das políticas públicas de educação superior voltadas para a construção de um sistema de educação brasileiro vinculado ao projeto de sociedade democrática.

É possível afirmar que continua a haver um clima favorável à avaliação institucional como processo contínuo de aprimoramento, nas suas dimensões interna e externa, faltando, entretanto, avançar ainda na construção de uma síntese compatível com o processo vivenciado internamente, em cada IES, a ser tornada pública, periodicamente, e que possa orientar efetivamente decisões institucionais e do Estado. A melhoria da qualidade da educação superior precisa, portanto, orientar políticas de expansão de sua oferta e promover o aprofundamento dos compromissos e responsabilidades sociais das IES.

Iniciativas como as do Programa Universidade para Todos (PROUNI), por exemplo, motivaram inovações no âmbito das instituiçôes, tanto do ponto de vista da formação (inserção de atividades culturais, uso da informática, domínio de idiomas, práticas de leitura e de compreensão de texto), como do ponto de vista financeiro (bolsas de estudo, empréstimo, mensalidade flexível) para assegurar a permanência de estudantes, cujo rebatimento no seu desempenho e na sua autoestima começa a ser desvelado, conforme estudo recente de Velloso (2009).

Assim, a discussão acadêmica e social de tópicos relacionados à avaliação necessita ter continuidade e envolver, necessariamente, IES, Comunidade acadêmica e sociedade, bem como multiplicar a construção de competências na área.

Um curso de pós-graduação de caráter interinstitucional proposto, inicialmente, pela professora Isaura Belloni, uma das pioneiras da avaliação da educação superior no país, ocorreu no segundo semestre de 2009 e foi concluído em junho de 2010 no Instituto MERCOSUl de 
Estudos Avançados (IMEA), da Universidade da Integração Latino-Americana (UNILA), sob patrocínio da Universidade Federal do Paraná (UFPR). Este espaço propiciou a realização de estudos que permitem avançar no conhecimento sistemático de efeitos produzidos pelo SINAES tanto nas IES como no seu entorno, bem assim, entre avaliadores e organismos responsáveis por sua implementação - CONAES, INEP e o próprio MEC. Aliás, esta é uma imposição do próprio processo avaliativo previsto na Lei n. 10.861/2004.

Importa, dessa forma, reunir estudos disponíveis, alguns deles financiados pelo INEP, com vistas a apreender os principais problemas enfocados para torná-los objeto de política educacional, bem como para aprimorar instrumentos de utilização e procedimentos de capacitação de avaliadores.

Por outra parte, os organismos implementadores do SINAES precisam não se deixar enredar pelos tempos estabelecidos na Lei e procurar alternativas que, respeitando o dispositivo legal, possam adaptar a sua execução ao próprio processo por ela desencadeado. Por exemplo, mantendo o ciclo do SINAES e do ENADE, excluir, por um período, amostras de cursos que têm tido desempenho positivo estável. Ou, ainda, que a avaliação institucional externa se circunscreva àquelas IES Com ICG e CPC problemáticos. Tais medidas indicariam, por exemplo, o reconhecimento de que a autoavaliação institucional constitui procedimento de melhoria institucional e de cumprimento da missão que se atribuiu às instituições e que avaliação, regulação e supervisão são maneiras de estimular a qualidade da formação ofertada e de suscitar o compromisso social das IES e não apenas mecanismo de competição.

Admitir diferenças e autonomia institucional, reconhecer a possibilidade de a formação também corresponder às necessidades do mercado de trabalho, como forma de atender às desigualdades sociais, e manter a dimensão formativa do SINAES, mesmo se a astuta criação de índices respondeu à cobrança provinda da sociedade, constituem, ao que parece, os principais desafios do SINAES, que completa, em 2009, o seu primeiro ciclo avaliativo.

Recebido em fevereiro de 2010 e aprovado em março de 2010. 


\section{Referências}

BORGES, M.C.A. Articulação entre discursos globais e locais na definição da interpretação legitima de universidade nas propostas de reforma da educação superior no Brasil. 2007. Tese (Doutorado em Sociologia) Programa de Pós-Graduação em Sociologia, Universidade Federal de Pernambuco, Recife.

BRASIL. Conselho Federal de Educação. Parecer MEC/CFE n. 977/65, de 3 de dezembro de 1965: Documenta, Brasília, DF, n. 44, p. 6786, dez. 1965.

BRASIL. Lei n. 5540, de 28 de novembro de 1968. Fixa as normas de organização e funcionamento do Ensino Superior. Brasília, DF: Congresso Nacional, 1968.

BRASIL. Lei n. 9131, de 24 de novembro de 1995. Altera dispositivos da Lei n. 424, de 20 de dezembro de 1961, e dá outras providências. Brasília, DF: Congresso Nacional, 1995.

BRASIL. Lei n. 9.394, de 20 de dezembro de 1996. Estabelece as diretrizes e bases da educação nacional. Brasília, DF: Congresso Nacional, 1996.

BRASIL. Lei n. 10.861, de 14 de abril de 2004. Institui o Sistema Nacional de Avaliação da Educação Superior - SINAES - e dá outras providências. Brasília, DF: Congresso Nacional, 2004.

CASTRO, M.H.M. Avaliação Institucional para a autogestão: uma proposta. Artigo preparado para a revista Ensaio: Avaliação e Políticas Públicas em Educação, Rio de Janeiro, 1995. (Separata).

CHAUI, M. Escritos sobre universidade. São Paulo: UNESP, 2001.

FREITAG, M. Le naufrage de l'université et d'autres essais d'épistemologie politique. Paris: La Découverte, 1995.

GOMES, A.M. Exame Nacional de Cursos e política de regulação estatal do ensino superior. Cadernos de Pesquisa, São Paulo, n. 120, p. 129-149, 2003. 
Avaliação e regulação da educação superior: conquistas e impasses

HOUSE, E.R. Tres perspectivas de la innovación educativa: tecnológica, política y cultural. Revista de Educación, Madrid, n. 286, p. 3-34, mayo/ago. 1988

HOUSE, E.R. Evaluacion, ética y poder. 3. ed. Madrid: Morata, 2000a. HOUSE, E.R. Tendencias en evaluacíon. Revista de Educacion, Madrid, n. 299, p. 43-55, sept./dec. 2000b.

HOUSE, E.R.; HOWE, K.R. Valores en evaluacion e investigacion social. Madrid: Morata, 2001.

HOWARTH, D. Discourse. Buckingham: Open University, 2000.

MARTINS, C.B. A reforma universitária de 1968 e a abertura para o ensino superior privado no Brasil. Educação \& Sociedade, Campinas, v. 30, n. 106, p. 15-35, jan./abr. 2009.

READINGS, B. The university in ruins. Cambridge: The Harvard University, 1996.

SANTOS, B.S. Crise da universidade. In: Santos, B.S. Pela mão de Alice: o social e o político na pós-modernidade. São Paulo: Cortez, 1995.

SANTOS, B.S.; ALMEIDA FILHO, N. A universidade do século XXI. Coimbra: Almedina, 2008.

SILVA JUNIOR, J.R.; CATANI, A.M.; GILIOLI, R. Avaliação da educação superior no Brasil: uma década de mudanças. Avaliação, Campinas, v. 8, n. 4, p. 9-29, 2003.

SISTEMA NACIONAL DE AVALIAÇÃO DA EDUCAÇĀO SUPERIOR (SINAES). Bases para uma nova proposta de avaliação da educação superior. Brasília, DF: Comissão Especial de Avaliação, 2003.

SGUISSARDI, V. Modelo de expansão do ensino superior no Brasil: predomínio privado/mercantil e desafios para a regulação e a formação universitária. Educação \& Sociedade, Campinas, v. 29, n. 105, p. 991-1022, 2008.

VELLOSO, J. Cotistas e não cotistas: rendimento de alunos da Universidade de Brasília. Cadernos de Pesquisa, São Paulo, v. 39, n. 137, p. 621-644, 2009. 
WEBER, S. Antecipações do debate internacional no Projeto de Lei da Reforma da Educação Superior - Texto apresentado na Mesa-Redonda "Globalização e Políticas de Educação Superior". In: Congresso Internacional da AFIRSE, v Colóquio Nacional. João Pessoa, 2009.

ZAINKO, M.A.S.; COELHO, R.H.N. Avaliação e reformas da educação superior no Brasil. In: EYNG, A.M.; GISI, M.L. Política e gestão da educação superior: desafios e perspectivas. Ijui: UNijuí, 2007. p. 89-134. 